University of New Hampshire

University of New Hampshire Scholars' Repository

2013

\title{
Observations of the Vertical Structure of Tidal Currents in Two Inlets
}

Thomas C. Lippmann

University of New Hampshire, Durham, t.lippmann@unh.edu

James D. Irish

University of New Hampshire, Durham

Jonathan Hunt

University of New Hampshire, Durham

Follow this and additional works at: https://scholars.unh.edu/ccom

Part of the Oceanography and Atmospheric Sciences and Meteorology Commons

\section{Recommended Citation}

Lippmann, Thomas C.; Irish, James D.; and Hunt, Jonathan, "Observations of the Vertical Structure of Tidal Currents in Two Inlets" (2013). Journal of Coastal Research. 1109.

https://scholars.unh.edu/ccom/1109

This Journal Article is brought to you for free and open access by the Center for Coastal and Ocean Mapping at University of New Hampshire Scholars' Repository. It has been accepted for inclusion in Center for Coastal and Ocean Mapping by an authorized administrator of University of New Hampshire Scholars' Repository. For more information, please contact Scholarly.Communication@unh.edu. 


\title{
Observations of the Vertical Structure of Tidal Currents in Two Inlets
}

\author{
Thomas C. Lippmann $\uparrow$, Jim Irish $\uparrow$, Jonathon Hunt $\uparrow$ \\ $\dagger$ Center for Coastal and Ocean Mapping, \\ University of New Hampshire, Durham, \\ $\mathrm{NH}, 03824$, USA \\ lippmann@ccom.unh.edu \\ jon.hunt@unh.edu

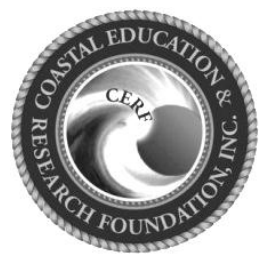

$\underline{\text { www.cerf-jcr.org }}$

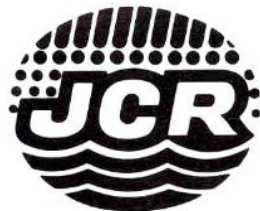

www.JCRonline.org

\section{ABSTRACT}

Lippmann, T. C., J. Irish, and Hunt, J., 2013. Observations of the vertical structure of tidal currents in two inlets. In: Conley, D.C., Masselink, G., Russell, P.E. and O'Hare, T.J. (eds.), Proceedings $12^{\text {th }}$ International Coastal Symposium (Plymouth, England), Journal of Coastal Research, Special Issue No. 65, pp. 2029-2034, ISSN 0749-0208.

Observations of the vertical structure of broad band tidal currents were obtained at two energetic inlets. Each experiment took place over a 4 week period, the first at Hampton Inlet in southeastern New Hampshire, USA, in the Fall of 2011, and the second at New River Inlet in southern North Carolina, USA, in the spring of 2012. The temporal variation and vertical structure of the currents were observed at each site with $600 \mathrm{kHz}$ and $1200 \mathrm{kHz}$ RDI Acoustic Doppler Current Profilers (ADCP) deployed on low-profile bottom tripods in 7.5 and $12.5 \mathrm{~m}$ water depths near the entrance to Hampton Inlet, and in 8 and $9 m$ water depth within and outside New River Inlet, respectively. In addition, a Nortek Aquapro ADCP was mounted on a jetted pipe in about $2.5 \mathrm{~m}$ water depth on the flank of the each inlet channel. Flows within the Hampton/Seabrook Inlet were dominated by semi-diurnal tides ranging $2.5-4 \mathrm{~m}$ in elevation, with velocities exceeding $2.5 \mathrm{~m} / \mathrm{s}$. Flows within New River inlet were also semi-diurnal with tides ranging about $1-1.5 \mathrm{~m}$ in elevation and with velocities exceeding $1.5 \mathrm{~m} / \mathrm{s}$. Vertical variation in the flow structure at the dominant tidal frequency are examined as a function of location within and near the inlet. Outside the inlet, velocities vary strongly over the vertical, with a nearly linear decay from the surface to near the bottom. The coherence between the upper most velocity bin and the successively vertically separated bins drops off quickly with depth, with as much as $50 \%$ coherence decay over the water column. The phase relative to the uppermost velocity bin shifts over depth, with as much as $40 \mathrm{deg}$ phase lag over the vertical, with bottom velocities leading the surface. Offshore, rotary coefficients indicate a stable ellipse orientation with rotational directions consistent over the vertical. At Hampton, the shallower ADCP, but still outside the inlet, shows a rotational structure that changes sign in the vertical indicating a sense of rotation at the bottom that is opposite to that at the surface. Within the inlet, the flow is more aligned with the channel, the decay in amplitude over the vertical is diminished, the coherence and phase structure is nearly uniform, and the rotary coefficients indicate no sense of rotation in the flow. The observations are qualitatively consistent with behavior described by Prandle (1982) for shallow water tidal flows.

ADDITIONAL INDEX WORDS: Inlet dynamics, tidal currents, vertical flow structure.

\section{INTRODUCTION}

The scales of bathymetric change in shallow water near river mouths and inlets ranges significantly in both time and space. This variability is a result of complex fluid-sediment interactions near the seabed, and is driven at both large and small scales by tides, surface gravity waves, wind driven flows, and river discharges. Adding to the complexity is mixing by differing water masses, and, of particular interest here, boundary layers that span the water column. Sediment transport is initiated and sustained in boundary layers, yet the mechanism by which large scale boundary layer flow (encompassing the range of depths in typical inlets, roughly 1-25 $\mathrm{m}$ ) impacts sea bed evolution is not clearly understood.

It has long been known that mean flow in shallow water has strong vertical structure owing to the presence of the sea bed and its "roughness" elements (Thornton and Guza, 1986; GarcezFaria, et al., 1998, 2000, and many others). It has also long been recognized that tidal flows on the continental shelf exhibit strong vertical variation in amplitude, phase (relative to the surface, for

DOI: 10.2112/SI65-343.1 received 07 December 2012; accepted 06 March 2013.

(c) Coastal Education \& Research Foundation 2013 example), and rotation (e.g., Maas and Vanharen, 1987; Visser, et al., 1994; Souza and Simpson, 1996; and others), a result dependent partially on Coriolis but primarily on the presence of the tidal flow boundary layer (Prandle, 1982). More recently, substantial vertical variation was observed in low frequency oscillations (order $200 \mathrm{~s}$ periods) in the surf zone associated primarily with broad band shear instabilities of the mean alongshore current (Lippmann, et al, sub judice). In just a few meter water depths the observed phase shifted as much as $50 \mathrm{deg}$, and with rotational components that reversed, leading to incoherent velocities separated vertically in space by just $1 \mathrm{~m}$. These flows were also found to be somewhat dependent on the cross-shore shear of the mean alongshore current, but again were primarily the result of the flow boundary layer which spanned the shallow surf zone depths for these few minute period waves (Lippmann and Bowen, sub judice). It is expected that the strong vertical variation observed on the shelf and in the surf zone is also present in river mouths and inlets, and that because of its substantial effects on the flow properties and structure, will have an impact on sediment transport and thus seafloor evolution.

Of particular importance to sediment transport is the coupling between the flow-fields and the seabed, manifested in bathymetric 
change and sedimentary evolution. The three-dimensional nature of inlets encompassing the inner shelf, surf zone, estuary, and river mouth creates significant difficulty for modeling. One particular limiting problem is that shallow flows (except for short period surface gravity waves) are universally associated with boundary layers that span the water column resulting in complex vertical amplitude, phase, and rotational structure in the flow. The problem is exacerbated by variation in sediment and bedform characteristics that evolve on timescales similar to the flow.

The overarching research objective is to examine the evolution of fine-scale features of the seabed and large-scale bathymetric evolution in response to the hydrodynamic forcing over the extent of the inlet, and to determine if the vertical structure of the flow field has an impact on seafloor bedform evolution. The principal objectives herein were to observe the vertical structure in the mean flow field (dominated by tidal currents) across the inner shelf and into the inlet, and examine the amplitude, phase, and rotational behavior as a function of depth.

\section{METHODS}

Field measurements were acquired at two inlets. The first was Hampton Inlet in New Hampshire, USA, in the fall of 2011. Figure 1 shows the location of three bottom mounted, upwardlooking acoustic Doppler current profilers (ADCPs) deployed in 7.5 and $12.5 \mathrm{~m}$ water depths on the inner shelf $(600 \mathrm{kHz}$ and 1200 $\mathrm{kHz}$ RDI Workhorse ADCPs, respectively), and in $3 \mathrm{~m}$ depth on the flank of the main inlet channel $(1 \mathrm{MHz}$ Nortek Aquapro Current Profiler). Currents were sampled continuously at $1-1.6$ $\mathrm{Hz}$ for 30 days. Time series were subsequently averaged over 5 min intervals yielding current estimates with errors on the order of $1 \mathrm{~cm} / \mathrm{s}$. Pressure sensors within the ADCP housing measured near-bottom pressures at the same rate. The offshore ADCP was mounted on a bottom weighted tripod approximately $1 \mathrm{~m}$ on a side

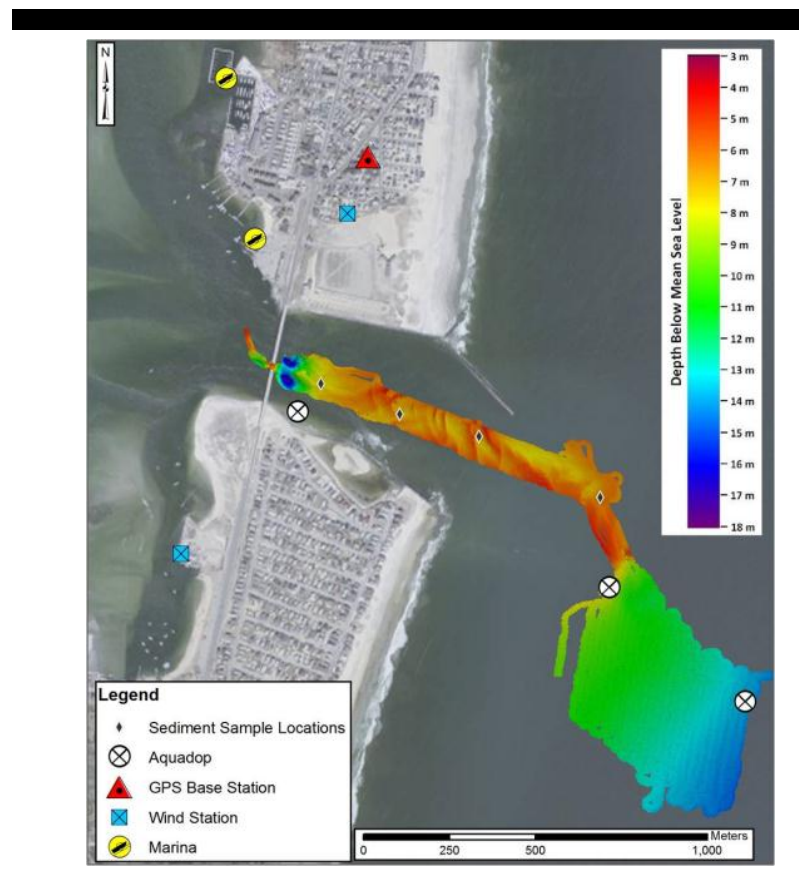

Figure 1. Field site for the Hampton/Seabrook Inlet experiment in southeastern New Hampshire on the northeast seaboard of the U.S. Color contours show the bathymetry relative to NAVD88 from multibeam surveys during the experiment. The location of ADCPs are shown in $12.5,7.5$, and $3 m$ water depths. and extending $0.63 \mathrm{~m}$ above the bottom. The first bin (closest to the transducer) was located $2.21 \mathrm{~m}$ above the bottom. Subsequent bins were spaced sequentially $1 \mathrm{~m}$ through the water column The inshore shelf ADCP located in $7.5 \mathrm{~m}$ water depth was mounted on a similar tripod that extended $0.52 \mathrm{~m}$ above the bottom, with the first velocity bin $1.43 \mathrm{~m}$ above the bottom and subsequent bins spaced $0.5 \mathrm{~m}$. To observe currents closer to the seabead at this location, a Nortek Aquadopp Acoustic Dopper current meter was included that measured velocities $0.70 \mathrm{~m}$ above the bottom. At the shallow inlet location, the Nortek Aquapro was mounted on a jetted pipe and placed horizontally on its side near the bed, and recorded its first bin $0.2 \mathrm{~m}$ above the bottom with bin spacing of $0.2 \mathrm{~m}$. Tides at Hampton ranged about $2.5-4 \mathrm{~m}$ in elevation, with maximum $5 \mathrm{~min}$ averaged currents around $2.5 \mathrm{~m} / \mathrm{s}$.

The second experiment was held at New River Inlet in North Carolina, USA, in the spring of 2012. Figure 2 shows the location of the same three bottom mounted, upward-looking ADCPs deployed in $9 \mathrm{~m}$ water depth seaward of the inlet $(600 \mathrm{kHz}$. RDI Workhorse ADCP), in $8 \mathrm{~m}$ water depth inside the main inlet channel (1200 kHz RDI Workhorse ADCP), and in $2.5 \mathrm{~m}$ depth on the flank of the inlet channel $(1 \mathrm{mHz}$. Nortek Aquapro Current Profiler). The same tripods and deployment strategies that were utilized in the Hampton field study were used here, and thus the distances above the bottom, the bin spacing, and the processing methods are the same. Currents again were sampled continuously at $1-1.6 \mathrm{~Hz}$ for 28 days. Tidal elevations at New River Currents ranged between $1-1.5 \mathrm{~m}$, with maximum observed $5 \mathrm{~min}$ averaged currents of about $1.5 \mathrm{~m} / \mathrm{s}$.

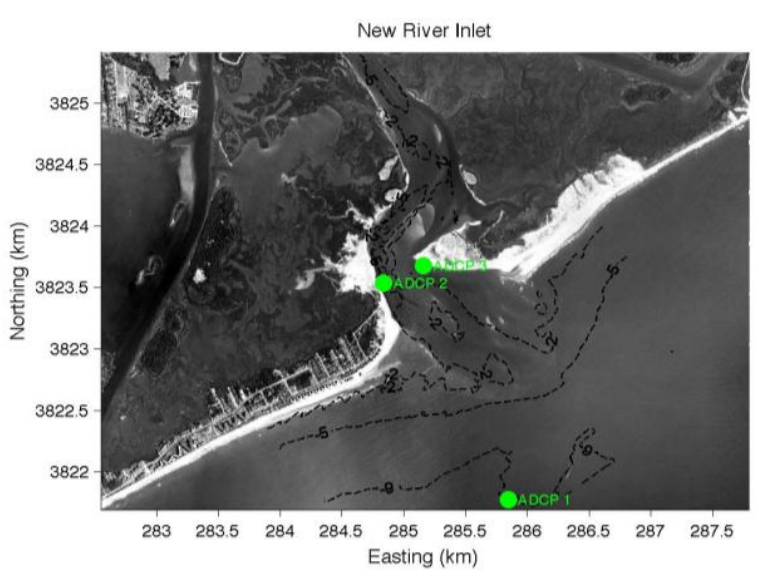

Figure 2. Google Earth Image of the New River Inlet Field site near Topsail Beach, NC, USA, showing the location of ADCP's (green dots), and bathymetric contours relative to NAVD88 (black dashed lines).

Data from the two experiments are used to examine the vertical structure of the mean currents at the semi-diurnal tidal frequency as a function of cross-shelf location. Spectra are calculated at each vertical bin from near the bottom to near the low tide elevation over the period of each experiment. Time series are mean-corrected, linearly detrended, and then a Hanning data window applied to reduce leakage. Spectra are band-averaged to yield between 44 and 50 degrees-of-freedom (DOF). Crossspectra between the near-surface bins and the successively separated vertical bins are computed in the same manner to determine the coherence and phase structure over the water column at the semi-diurnal tidal frequency $\left(0.08 \mathrm{hr}^{-1}\right)$. 
Rotary parameters are computed following Gonella (1972; formulas are omitted for brevity). There are three basic rotary parameters. The first is the rotary coherence (or stability) that describes how coherently the bi-directional components of the velocity are oscillating. Analogous to the cross-spectral coherence, the rotary coherence is bounded by 0 and 1 and has well understood significance levels on zero coherence. The second parameter describes the orientation of the ellipse major axis inscribed by the flow in phase space. For incoherent rotary motion the ellipse orientation has no meaning and the flow does not have a stable rotary motion. The third parameter is the rotary coefficient that describes the rotational nature of the flow at that particular frequency, and is bounded by 1 and -1 . When the rotary coherence is significant, then the rotary coefficient describes the sense of rotational motion, cyclonically or anti-cyclonically. When the coefficient is zero, there is no rotational motion and the flow oscillates along a trajectory aligned with the direction indicated by the ellipse orientation.

\section{RESULTS}

Bottom pressure spectra for the 30 day time series are obtained from pressure sensors within the ADCP housings. The pressure spectrum (normalized by density, $\rho$, and gravity, $g$ ) for the offshore sensor in $12.5 \mathrm{~m}$ water depth at Hampton is shown in Figure 3. The most dominant signal is at the broad banded semidiurnal tidal frequency (centered at $0.08 h r^{-1}$ ), at least 2 orders of magnitude higher than longer period fluctuations and several orders of magnitude higher than shorter periods. Owing to the 5 $\min$ averages, the Nyquist frequency is at $6 h r^{-1}$. Also shown in
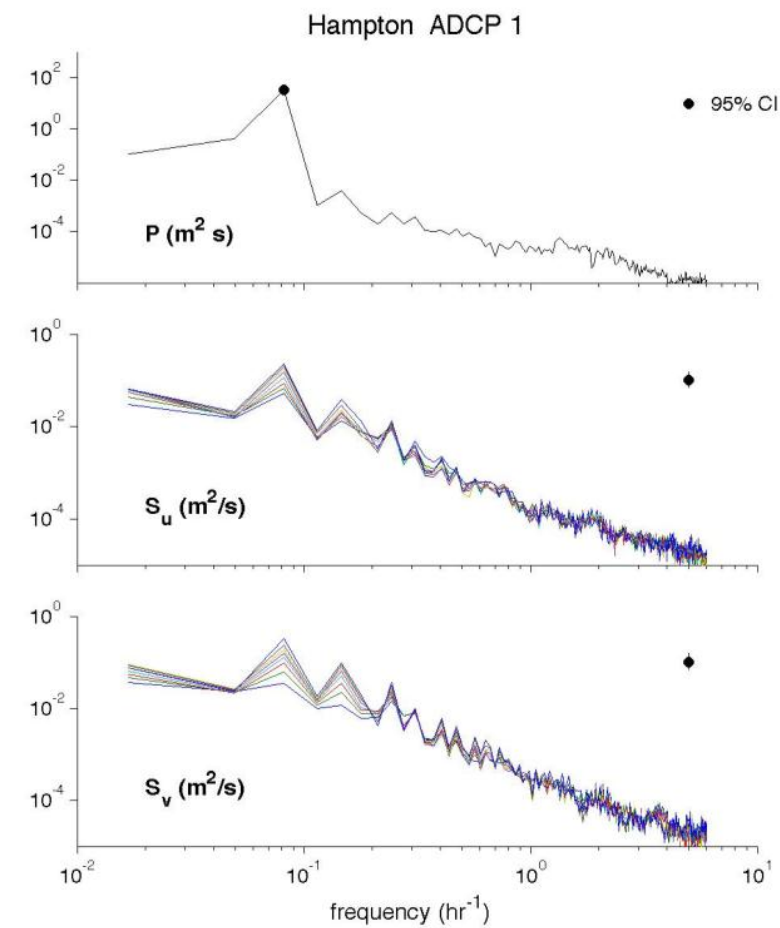

Figure 3. Spectral densities on log-log axes from the seaward sensor (ADCP 1) at Hampton. (upper panel) Bottom pressure (normalized by $\rho g$ ). (middle panel) East-west velocities at each vertical bin. (lower panel) North-south velocities at each vertical bin. The $95 \%$ confidence intervals are indicated on each panel.

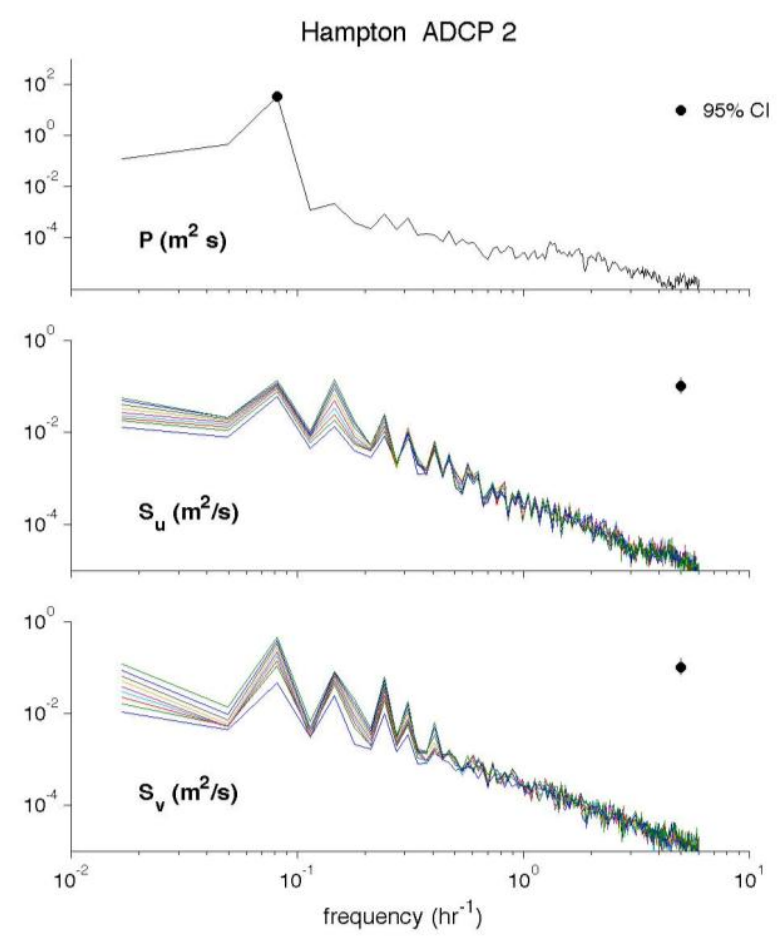

Figure 4. Same as Figure 3 for the inshore shelf sensor (ADCP 2) at Hampton.
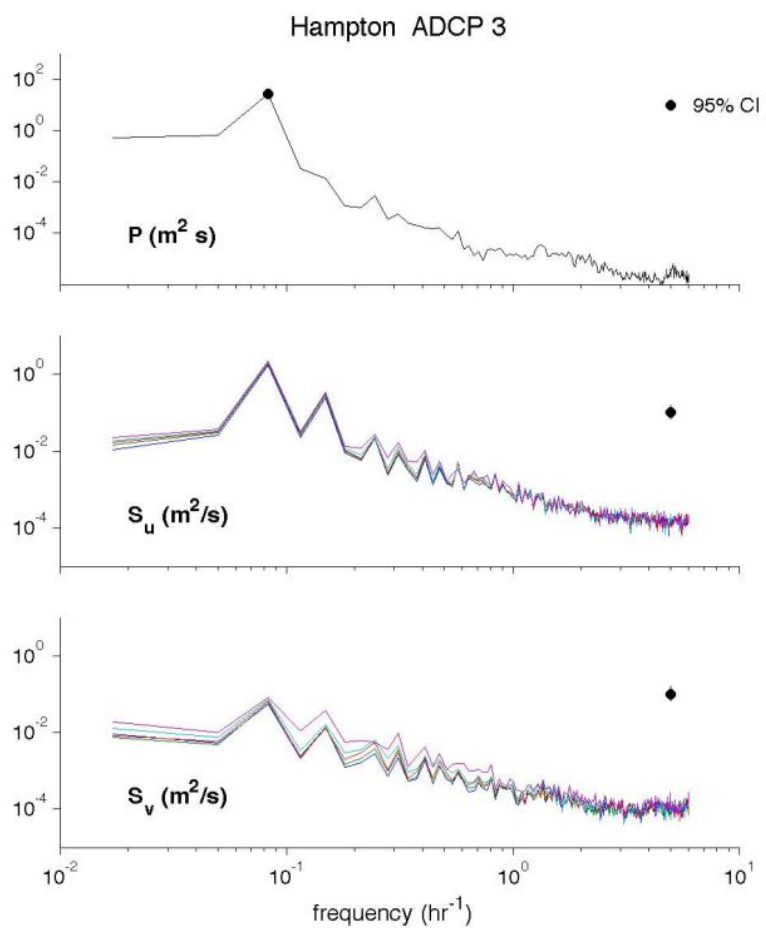

Figure 5. Same as Figure 3 for the inlet location (ADCP 3) at Hampton. 
Figure 3 are spectra from each bi-directional component of the flow (east-west, $u$, and north-south, $v$ ) at each velocity bin. The broad semi-diurnal oscillations are again dominant, although there is significant energy at higher tidal harmonics and other higher frequencies. Also apparent is that the energy at the semidiurnal period varies with depth above the bottom with lower amplitudes closer to the bed (as will be discussed later). The corresponding pressure and velocity spectra for data obtained at the inshore shelf and inner inlet locations at Hampton are shown in Figures 4 and 5. A similar pattern of pressure and flow variation is observed here as with the offshore spectra. Data from the three sensors at New River show similar behavior and are not shown for brevity.

In the following, we examine how cross-spectral and rotary parameters at the broad semidiurnal tidal frequency $\left(0.08 h r^{-1}\right)$ vary with depth. We will compare the coherence and phase shift relative to the uppermost sensor for each component of velocity separately, and then examine how the rotary coherence (stability), ellipse orientation, and rotary coefficient vary with depth.

First we examine the vertical structure of the semi-diurnal tidal oscillation at the seaward location (ADCP 1) at Hampton. The vertical structure of spectral densities, $S_{u}$ and $S_{v}$, coherence squared $\left(\operatorname{coh}_{\mathrm{u}}{ }^{2}\right.$ and $\left.\operatorname{coh}_{\mathrm{v}}{ }^{2}\right)$, and phase $\left(\theta_{u}\right.$ and $\left.\theta_{v}\right)$, relative to the uppermost bin, and rotary parameters are shown relative to the distance above the bottom in Figure 6. The spectral densities of each component of the flow decays nearly linearly over depth indicating a strong influence of the bottom boundary layer on the

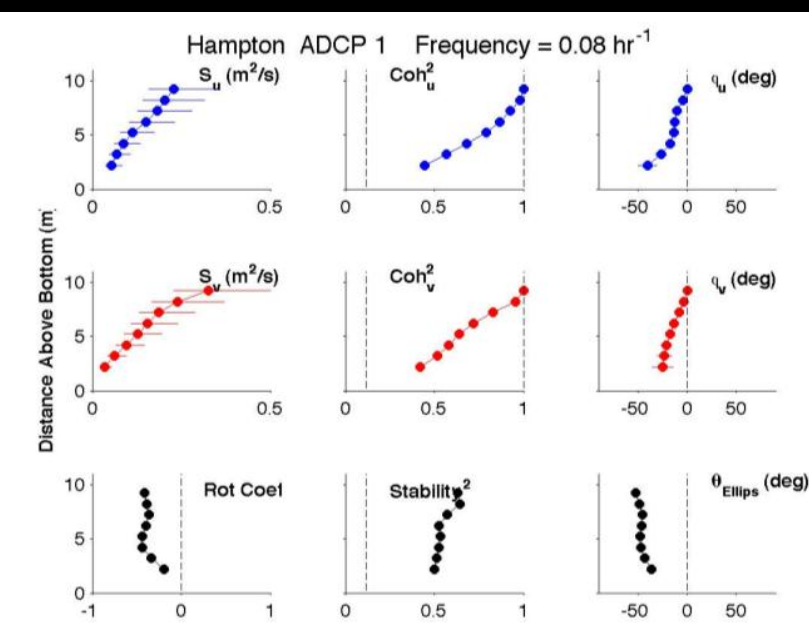

Figure 6. Vertical structure of east-west velocity (top panels), north-south velocity (middle panels), and rotary parameters (bottom panels) at the semidiurnal tidal frequency $\left(f=0.08 \mathrm{hr}^{-1}\right)$ from the offshore ADCP location at Hampton. (top and middle left) Spectral densities as a function of distance above the bottom $(m)$. (top and middle center) Coherence relative to the uppermost sensor. (top and middle right) Phase ( $d e g$ ) relative to the uppermost sensor. Negative phases indicate the bottom is leading the surface. Rotary coefficient (left bottom), rotary coherence (center bottom), and rotary ellipse orientation (deg; right bottom) are also shown as a function of distance above the bottom. The spectra were computed over the 30 day record with 50 degrees of freedom. The $95 \%$ confidence interval for the spectral densities are shown as the horizontal dash-dot lines. The 95\% significance level for zero coherence is shown with the dashed line in the three center panels. The corresponding $95 \%$ confidence intervals for the phase estimates are shown as the horizontal lines through the data points.

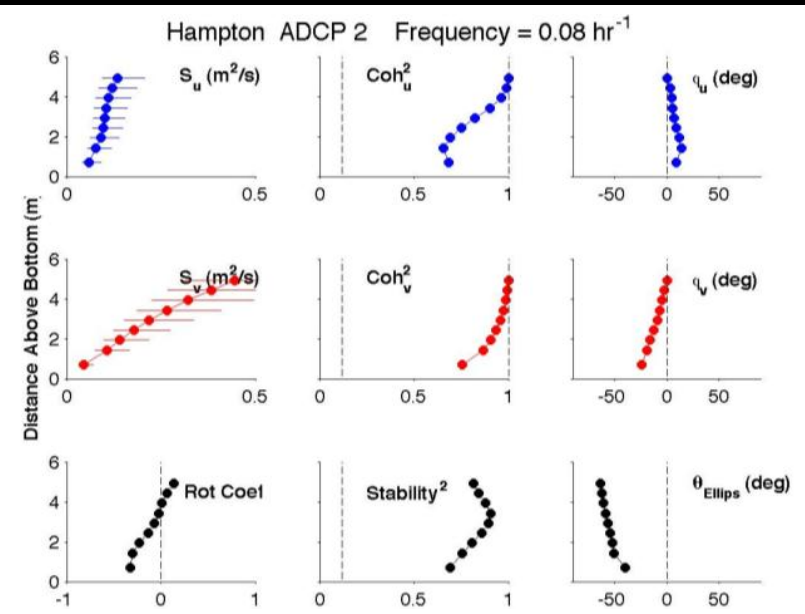

Figure 7. Same as Figure 6 for the ADCP located in $7.5 m$ water depth at Hampton.

flow. There is also a sharp drop off in coherence with depth for both components of the flow, decaying in an approximately linearly manner to about $40 \%$ over the water column. The phase also shifts linearly with depth, with the bottom flows leading the surface flows by as much as 40 degrees.

Also observed in the data is that the rotary coherence is significantly non-zero (ranging between 0.5 and 0.7 ). The ellipse orientation of the major axis is about 50 degrees with slight rotation with depth indicating a turning of the flow of about 10 degrees back to the north towards the bottom. The rotary coefficients are negative indicating an anti-cyclonic rotation that becomes less rotary-like and more closely aligned with the ellipse orientation with depth.

We next examine the structure of the semidiurnal tide at the shallower shelf location (ADCP 2) at Hampton (in about $7.5 \mathrm{~m}$ water depth) just outside the mouth of the inlet (Figure 7). At this location, the flow is more strongly aligned with the depth contours

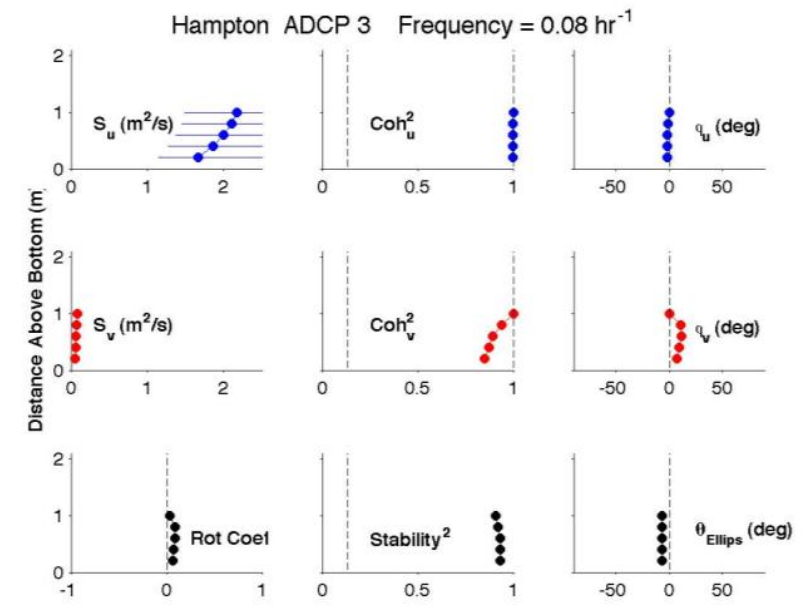

Figure 8. Same as Figure 6 (with 44 DOF) for the ADCP located on the flank of the inlet channel at Hampton. 


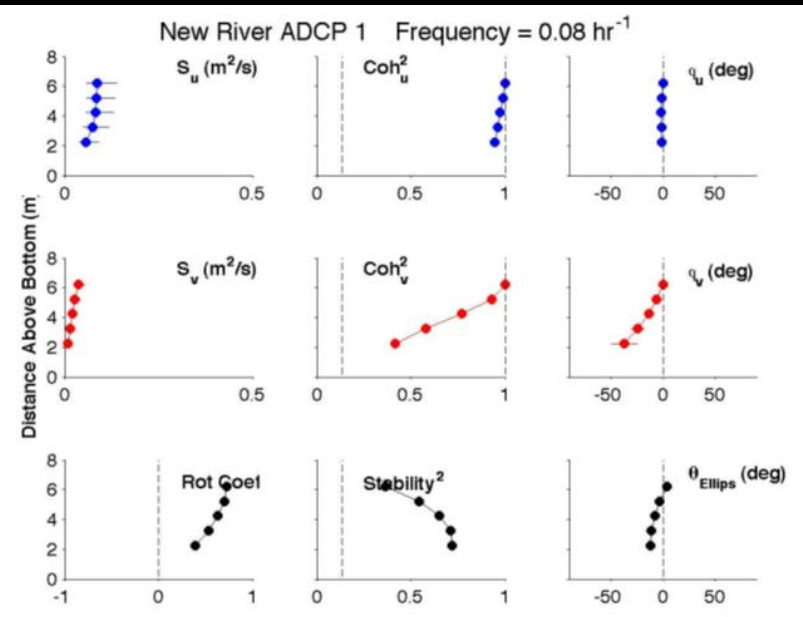

Figure 9. Same as Figure 6 (with 44 DOF) for the ADCP located in $9 m$ water depth just outside the inlet at New River.

indicated by the higher north-south spectral densities relative to the east-west component. The spectral energy again decays nearly linearly with depth, particularly strongly for the north-south component of the flow. The coherence drops off to between 60 and $70 \%$ relative to the surface. The phase shifts for the northsouth flow are negative relative to the surface, indicating the bottom north-south flow leads the surface. However, phase shifts for the east-west component of the flow shifts positively with depth, indicating that the east-west bottom flows lag the surface. The rotary coherence is significantly non-zero throughout the water column, with an ellipse orientation of the major axis of about 60 degrees. The ellipse orientation shifts about 20 degrees over the vertical, indicating a turning of the flows to a more northerly direction near the bottom. The rotary coefficients are non-zero and, interestingly, change sign over the vertical with a positive (cyclonic) rotation at the surface and a negative (anticyclonic) rotation near the bottom. Changes over the water column in the phase leads of the north-south and east-west components of the flow and in the direction of the rotational nature of the tidal flow suggests a complex flow behavior indicative of a strong boundary layer influence (e.g., Prandle, 1982).

The vertical structure of the ADCP data on the flank of the inlet channel (ADCP 3) at Hampton is shown in Figure 8. The location of this sensor was off to the side of the channel and does not sample the strongest flows more centered in the inlet. At low tides, the depth of water is about $1 \mathrm{~m}$ and thus the vertical structure does not span a significant range in depth. The flows observed here show much stronger east-west currents aligned with the main channel, and do indicate a decay over depth consistent with boundary layer influence. These strong east-west flows have uniformly strong coherence over the $1 \mathrm{~m}$ water column examined and show in-phase bottom currents relative to the surface. The north-south flows (aligned approximately perpendicular to the main channel) are weaker and show small coherence drops and phase shifts over the vertical. The rotary parameters show a uniformly aligned major axis and slightly positive rotary coefficient over the vertical. Although not placed in the center of the channel, these observations are consistent with the more optimally placed inlet sensors at New River (discussed next).

The vertical structure from the offshore location (ADCP 1) at New River is shown in Figure 9. The broad semidiurnal tidal flows observed here are weaker than at similar locations near Hampton, a result of the lower tide range at New River (about half of that at Hampton). The spectral energies show some vertical

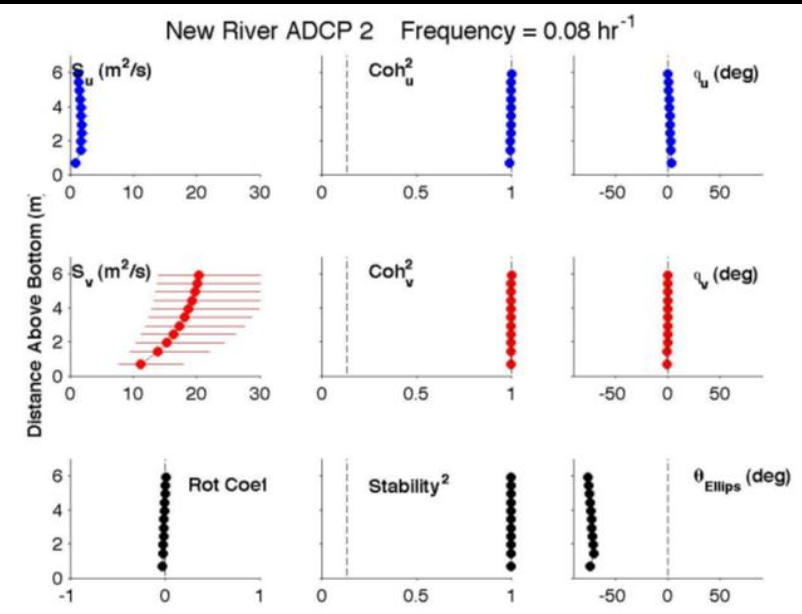

Figure 10. Same as Figure 9 (with 44 DOF) for the ADCP located in $8 \mathrm{~m}$ water depth inside the main channel of the inlet at New River.

decay with depth, and for the north-south component of the flow have a strong drop in coherence (40\%) and phase lag (-40 degrees) at the bottom. The east-west flows are more coherent throughout the water column and show no phase shift. The rotary parameters indicate a turning of the major ellipse axis oriented nearly northsouth at the surface to about 10 degrees toward the west at the bottom. The positive rotary coefficient indicates a cyclonic rotation that becomes less rotational with depth. This behavior is qualitatively similar to the changes in the vertical structure between the $12.5 \mathrm{~m}$ and $7.5 \mathrm{~m}$ ADCPs at Hampton.

The location of ADCP 2 at New River (Figure 10) is directly in the heart of the main inlet channel. The north-south flows are significantly stronger than in the east-west (more across-inlet) direction. Although there is strong vertical decay in the spectral energies, the coherence and phase structure is uniform over the water column with the bottom and surface flows in-phase. The rotary parameters indicate a nearly uniform ellipse orientation aligned with the bathymetric contours at this location, with a vertical shift of about 5 degrees to the north toward the bottom. The flow is not rotary (near zero rotary coefficient) over the water column with the flows oscillating along the orientation of the major ellipse axis. The location of ADCP 3 at New River (Figure 11 ) is across the inlet from ADCP 2 toward the northern side of the inlet. The vertical structure here is similar in character to the sensor in the heart of the channel, except that the flows are weaker and more aligned toward the east-west direction, approximately aligned with the bathymetric contours

\section{DISCUSSION}

In tidal flows on the continental shelf, the bottom boundary layer modifies the flow profile in such a way that a rotational change is imparted on the flow over the vertical (Prandle, 1982; Soulsby, 1991). In their work, velocities near the bed are attenuated relative to the surface flow, and a phase shift is induced such that the bottom leads the surface. Our observed velocity decay and phase variation over the vertical are qualitatively consistent with that predicted by Prandle's development. They discuss the three-dimensional properties using complex representation of the velocities (as in our rotary spectral analysis) and show that cyclonic and anti-cyclonic behavior is expected.

Following Prandle's development, Lippmann and Bowen (sub judice) showed that strong vertical variation in oscillating surf 
zone currents (instabilities of the longshore current) is also predicted, including rotational change over the vertical and large phase leads (and lags) at the bed. The behavior is strongly dependent on the bottom shear stress that determines the nature of the boundary flow that extends throughout the water column for tidal flows in water depths examined herein.

Results have implications for interpreting data in shallow water where tidal flows are important, particularly for remote sensing techniques that observe surface velocities but not subsurface flows. Similarly, modeling studies should consider the strong variation in flow that can occur in shallow water, particularly when considering sediment transport formula that depend on the current directions as a function of position in the water column.

It should be noted that spectra computed herein have frequency bandwidth that is broad relative to tidal constituents. Broad tidal frequencies are approximately centered about $0.08 \mathrm{hr}^{-1}$, and dominated, but not solely influenced, by the M2 tidal constituent at $0.0805 \mathrm{hr}^{-1}$. As a consequence, the behavior over the vertical of the individual tidal constituents within the broad frequency band of interest is likely giving us the sharp drop off in coherence. This aspect of the results is the subject of ongoing research.

Finally, the observational results condsidered here do not consider possible effects of stratification or inlet discharge on the vertical structure (e.g., Visser, et al., 1994; Souza and Simpson, 1996; and others). It is plausible that these effects can modify the vertical behavior of the tidal flows. Although measurements of the hydrography in the region (not discussed) suggest that neither the Hampton nor New River sites have strong stratification or fresh water discharge, their effects can not be discounted.

\section{CONCLUSIONS}

Observations of broad banded semidiurnal tidal currents just outside and within two inlets show strong vertical structure in both amplitude and direction that depends on spatial location relative to the inlet mouth. Observations from the ADCPs on the inner shelf show significant vertical structure in energy, phase, and rotation at tidal frequencies (around $0.08 \mathrm{hr}^{-1}$ ) not previously observed in this shallow region. Energy levels in both the cross-shore and alongshore components of the flow decays nearly linearly over

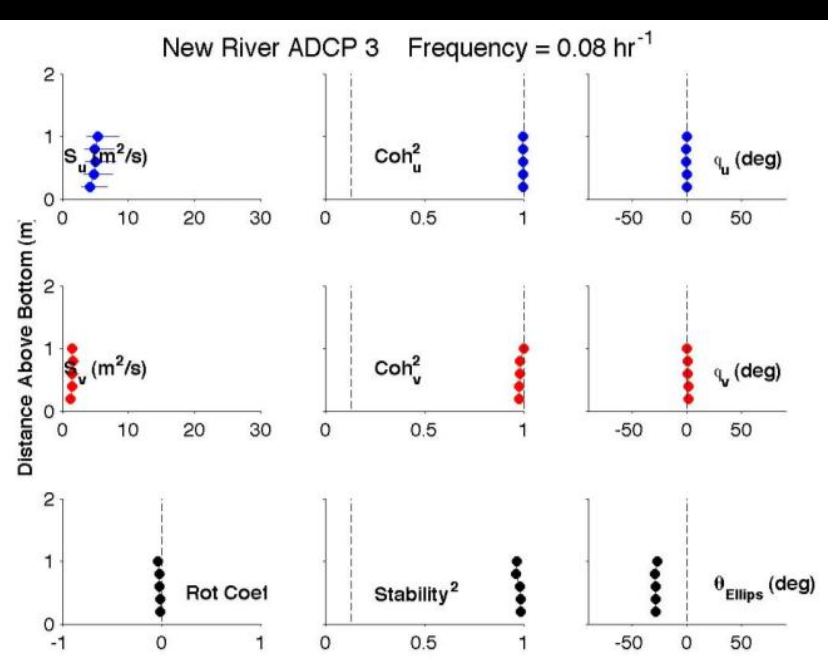

Figure 11. Same as Figure 9 (with 44 DOF) for the ADCP located in $2.5 \mathrm{~m}$ water depth on the flank of the inlet channel at New River. depth, suggesting the presence of a bottom boundary layer that spans the water column. The coherence between the currents at depth and the near-surface drops off quickly with depth for both components of the flow, with as much as $50 \%$ coherence drop over the water column. Additionally, the phase relative to the surface shifts approximately linearly over depth, with as much as $40 \mathrm{deg}$ phase lags from top to bottom. Offshore, the bottom flows lead the surface whereas in shallower water the east-west flows lag the surface. Spatially and vertically varying phase structure results in rotational structure that varies across the array dimensions on the inner shelf. The ellipse orientation (obtained from rotary spectral analysis) at tidal frequencies turns up to 20 deg over the water column. Not surprisingly, the rotary coefficients are non-zero confirming the rotary nature of semidiurnal tidal motions; however, while the rotation is anti-cyclonic over the water column at deeper shelf locations, the rotary coefficients closer to the inlet shifts linearly and changes sign over the water column, indicating that the surface tidal flow at the shallower location rotates cyclonically while the near-bottom flow rotates in the opposite direction. Inside the inlet, the flow is predominately aligned with the channel, and with much more uniform coherence and phase structure over the water column

The observed amplitude and phase behavior is qualitatively predicted by simple boundary layer theory for tidal flows in shallow water (Prandle, 1982). The rotational structure suggests possible modulation of tidal currents by stratification (Visser, et al., 1994; Souza and Simpson, 1996), inlet discharge, or surface wind-driven currents. The non-uniform vertical structure has implications to the interpretation of field data, particularly from remote sensing sources, and horizontal mixing on the inner shelf. The relationship of the flow field to observed bedform evolution and bottom roughness is part of ongoing investigations.

\section{ACKNOWLEDGEMENTS}

The work described in this publication was supported by the U.S. Office of Naval Research and the U.S. National Oceanic and Atmospheric Administration. The New River Inlet data were obtained as part of the larger, collaborative RIVET study and benefited from the many participants of the experiment.

\section{LITERATURE CITED}

Garcez Faria, A., E.B. Thornton, T.P. Stanton, C.V. Soares, and T.C. Lippmann, 1998. Vertical profiles of longshore currents and related bed shear stress and bottom roughness. J. Geophy. Res. 103(C2), 3217-3232.

Garcez Faria, A., E.B. Thornton, T.C. Lippmann, and T.P. Stanton, 2000 Undertow over a barred beach. J. Geophys. Res. 105(C7),16.999-17,010

Lippmann, T.C., E.B. Thornton, and T.P. Stanton, 2012. The vertical structure of low frequency motions in the nearshore, Part 1: Observations. J. Phys. Oceanogra., sub judice.

Lippmann, T.C., and A.J. Bowen, 2012. The vertical structure of low frequency motions in the nearshore, Part 2: Theory. J. Phys. Ocean., sub judice.

Maas, L.R.M., and J.J.M. Vanharen, 1987. Observations on the vertical structu of tidal and inertial currents in the cenral north-sea. J. Mar. Res. 45(2), 293-318.

Prandle, D., 1982. The vertical structure of tidal currents and other oscillatory flows. Cont. Shelf Res., 1(2), 191-207.

Soulsby, R.L., 1990. Tidal-current boundary layers. in The Sea, Vol.9, Ocean Engineering Science, B. Le Mahoute and D.M. Hanes, Eds. Wiley and Sons, pp. 523-566.

Souza, A.J., and J.H. Simpson, 1996. The modification of tidal ellipses by stratification in the Rhine Rofi. Cont. Shelf Res., 16(8), 997-1007.

Thornton, E.B., and R.T. Guza, 1986. Surf zone longshore currents and random waves: Field data and models. J. Phys. Ocean., 16, 1165-1178.

Visser, A.W., AJ. Souiza, K. Hessner, and J.H. Simpson, 1994. The effect of stratification on tidal current profiles in a region of freshwater influence. Oceanologica Acta, 17(4), 369-381. 